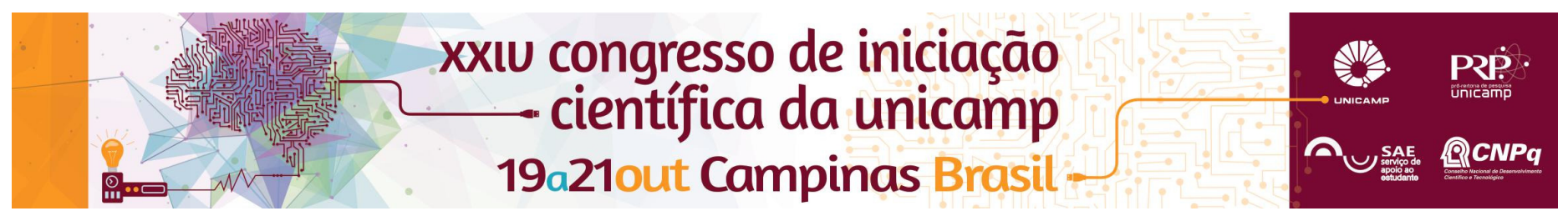

\title{
Development of semiconductor catalysts for enzyme mimic based on cerium oxide nanoparticles system.
}

\author{
Lidiane O. Pinto* (IC), Larissa H. Oliveira (PQ), Fernando A. Sigoli (PQ), Italo O. Mazali (PQ)
}

\begin{abstract}
In this work, we study the catalytic activity of cerium oxide nanoparticles supported on SBA-15 silica as enzyme mimetic systems.
\end{abstract}

\section{Key words: \\ Nanoparticles, Enzyme Mimic, Biosensors}

\section{Introduction}

Immunosensors are a kind of biosensors in that the receivers are antibodies or antigens. The sensibility of these systems can be optimized by the use of enzymes. Nature enzymes are unstable, and can be easily denatured by environmental changes, since its catalytic activity depends of the integrity and native conformation of the protein. Nature enzymes can be replaced by nanomaterials, due to its high surface area and capacity of adsorption of molecules. Recently, it was found that the $\mathrm{CeO}_{2}$ nanoparticles (CeNPs) have an antioxidant activity at physiological $\mathrm{pH}$ values and several studies have reported the biomedical application of these systems. In this context, the objective in this work is the study of CeNPs as an enzyme mimetic system. The materials were synthesized by the impregnation-decomposition cycles methodology (IDC), allowing a good size control and an uniform distribution of the precursor in the host silica ${ }^{1,2}$. A detailed study of particle size control and synergistic effects were held in order to understand how these effects would be able to modify its biosensing performance.

\section{Results and Discussion}

Mesoporous silica (SBA-15) was obtained, with tunable large uniform pores sizes (up to $300 \AA$ ). ${ }^{3}$ The hexagonal array of pores in range of $7.93 \mathrm{~nm}$ was calculated by $\mathrm{N}_{2}$ adsorption -desorption analysis and transmission electron microscopy (MEV).

Nanometric ceria-decorated SBA-15 was prepared by the impregnation of SBA-15 pores by a solution of cerium (III) 2-ethylhexanoate $\left(0.5 \mathrm{~mol}^{-1}\right)$, followed by its thermal decomposition at $700^{\circ} \mathrm{C}$. Analysis of $\mathrm{X}$-ray diffraction (XRD), Small-Angle X-ray Scattering (SAXS), Raman and UV-vis Absorption Spectroscopy was used to observe the relationship between the number of successive IDC and the particle size, being set as 4,6 and 8. XRD patterns indicated the formation of $\mathrm{CeO}_{2}$ fluorite phase with $\mathrm{Fm} 3 \mathrm{~m}$ space group. According to UV-Vis spectra, the band gap energy does not change with the increase of IDC number. Besides that, these values showed that the CeNP has a lot of structural defects. SAXS pattern indicated that as the IDC number increase, the pore diameter decrease, and it could be an evidence that the CeNP was formed inside SBA-15 mesoporous. These data are in accordance with $\mathrm{N}_{2}$ desorption-adsorption analysis, where a decrease in mean pore size of SBA-15 was observed. The resulting systems exhibit a peroxidase-like activity and catalyzes the $\mathrm{H}_{2} \mathrm{O}_{2}$-mediated oxidation of $3,3^{\prime}, 5,5^{\prime}$-tetramethylbendizine (TMB) to produce a blue colored product. The kinetics of the catalytic reaction was monitored by UV-Vis absorption band at $650 \mathrm{~nm}$ as function of time. Some factors were analyzed to optimize the colorimetric system: $\mathrm{pH}, \mathrm{H}_{2} \mathrm{O}_{2}$, TMB and catalyst concentration. The results indicated that this catalytic system accelerate the electron-transfer process and facilitate radical generation at the surface of the CeNPs. The maximum catalytic performance was observed for 8 IDCs, so it indicates that the nanoparticles size also affects the catalytic performance.

\section{Conclusions}

Well-ordered hexagonal mesoporous silica (SBA-15) was formed and ceria nanoparticles supported on SBA-15 with tunable particle size were prepared by IDC methodology. The results confirmed that CeNPs are formed inside the SBA- 15 pores and increase in size upon IDC number. $\mathrm{CeO}_{2}$ supported on SBA-15 silica are effective as catalyst and possess a peroxidase-like activity. The catalytic performance also showed that these systems potential materials in biosensing of biological molecules.

\section{Acknowledgement}

CNPq/PIBIC, FAPESP, INOMAT, CAPES, IQ-UNICAMP, LNNano.

\footnotetext{
${ }^{1}$ Fattori, N.; Maroneze, C. M.; Costa, L. P.; Strauss, M.; Mazali, I. O.; Gushikem, Y. Colloids Surf. A : Physichem. Eng. Aspects 2013,437, 120126

${ }^{2}$ Correa-Duarte, M. A.; Kobayashi, Y.; Caruso, R. A.; Liz-Marzán, L. M. J. Nanosci. Nanotechno. 2001, 1, 95.

3 Zhao, D.; Feng, J.; Huo, Q.; Melosh, N.; Fredrickson, G. H.; Chmelka, B. F.; Stucky, G.D. Science 1998, 279, 548.
} 